\title{
The right thing at the right time: why ostensive naming facilitates word learning
}

\section{Emma L. Axelsson, Kirsten Churchley and Jessica S. Horst*}

WORD Lab, School of Psychology, University of Sussex, Brighton, UK

Edited by:

Catherine M. Sandhofer, University of California Los Angeles, USA

\section{Reviewed by:}

Hanako Yoshida, University of

Houston, USA

Caitlin Fausey, Indiana University, USA

${ }^{*}$ Correspondence:

Jessica S. Horst, WORD Lab, School of Psychology, University of Sussex,

Pevensey 1 Building, Falmer, Brighton BN1 9OH, UK.

e-mail: jessica@sussex.ac.uk
The current study examines how focusing children's attention immediately after fast mapping improves their ability to retain novel names. Previous research suggests that young children can only retain novel names presented via referent selection if ostensive naming is provided and that such explicit naming works by increasing children's attention to the target and decreasing their attention to the competitor objects (Horst and Samuelson, 2008). This explanation of the function of ostensive naming after referent selection trials was tested by drawing 24-month-old children's attention to the target either by illuminating the target, covering the competitors, or both. A control group was given a social pragmatic cue (pointing). Children given social pragmatic cue support did not demonstrate retention. However, children demonstrated retention if the target object was illuminated, and also when it was illuminated and the competitors simultaneously dampened. This suggests that drawing children's attention to the target object in a manner that helps focus children's attention is critical for word learning via referent selection. Directing attention away from competitors while also directing attention toward a target also aids in the retention of novel words.

Keywords: language acquisition, word learning, attention, fast mapping, referent selection

\section{INTRODUCTION}

The first 2 years of childhood are filled with remarkable accomplishments. During this short time, children's weight quadruples and their height nearly doubles (e.g., Lampl et al., 1992; Gokhale and Kirschner, 2003), they learn fine motor skills such as grasping (e.g., Thelen et al., 1993; Needham et al., 2002), gross motor skills such as crawling (e.g., Adolph et al., 1998) and walking (e.g., Adolph and Eppler, 1998), and begin acquiring social skills such as turn-taking (e.g., Rutter and Durkin, 1987). Importantly, they also typically acquire a productive vocabulary of around 300 words (Fenson et al., 1994). With so much to learn in such a short time, children make each of these accomplishments appear effortless, but none are achieved overnight and most require months of hard work.

Building a vocabulary is certainly hard work - even for skilled language learners - because acquiring new words is a complicated process where learning each new word involves not only fast, but also slow mapping (Carey, 1978; Capone and McGregor, 2005; Horst and Samuelson, 2008). Fast mapping occurs the first time a novel word is encountered when the child quickly forms a rough, initial hypothesis of its meaning (Carey, 1978). For example, if a child sees a book, a cup, and a novel electronic gadget, and hears the novel word $i P a d$, the child can reliably determine that iPad refers to the gadget. That is, the child can use existing vocabulary (i.e., book and cup) to determine the referent of the novel name via process-of-elimination (see also Halberda, 2003).

However, simply forming this initial mapping does not mean that the child has fully learned the word (Riches et al., 2005; Horst and Samuelson, 2008; Mather and Plunkett, 2009). Rather, full word learning (slow mapping) occurs gradually (for a similar argument see Horst et al., 2006; McMurray et al., 2009). To fully learn a new word, the child must form a robust memory representation of the word-object association that can be recalled later, often in a new context (e.g., when the iPad is next to another novel object, such as a laser pointer). This stable association typically emerges over a longer period of time as the child repeatedly encounters the new name and its referent (Horst et al., 2006; Horst and Samuelson, 2008; Smith and Yu, 2008). Specifically, the statistical regularity with which a new name (e.g., iPad) and its referent (e.g., the gadget) co-occur helps strengthen a child's remembered association.

Thus, the word learning process encompasses both fast and slow mapping. However, to complete both phases effectively, the child must attend to different things at different times. Put another way: the child must attend to the right thing(s) at the right time. Specifically, because referent selection (cf. fast mapping) is a process-ofelimination task, the child must attend to the known competitors (i.e., the book and the cup) to exclude them as possible referents. In contrast, to be able to later recall the name-object association in a new context, the child must have attended to and encoded something about the novel object (i.e., the iPad). Importantly, the child must avoid exclusively attending to the known competitors when making the initial name-object mapping. Recent research suggests that children first attend to the known competitors before attending to the novel object (Halberda, 2003), but forget information about the novel name-object mapping after a short delay (Horst and Samuelson, 2008). Clearly, then, attention to the competitors plays an important role in children's ability to learn words via referent selection. 
Although fast mapping has been extensively studied since the term was coined in the late 1970s (e.g., Heibeck and Markman, 1987; Golinkoff et al., 1992; Mervis and Bertrand, 1994; Woodward et al., 1994; Markson and Bloom, 1997), how children complete the gradual slow mapping phase after encountering novel names via referent selection is less well understood because very few studies have tested both referent selection and retention (for a review see Horst and Samuelson, 2008). Further, almost all of the studies that have tested children's retention for novel names have used some form of ostensive naming. However, ostensive naming has been performed in different ways across studies making it difficult to specifically determine how it facilitates word learning via referent selection and how it supports the transition from initial fast mapping to gradual slow mapping.

In some studies, children do not engage in referent selection and are instead simply told the novel label (e.g., Woodward et al., 1994; Markson and Bloom, 1997; Waxman and Booth, 2000; Childers and Tomasello, 2002) or the name-object associations are reviewed prior to test (e.g., Goodman et al., 1998). In some cases, only one out of an array of novel objects is named (e.g., Woodward et al., 1994; Markson and Bloom, 1997; Waxman and Booth, 2000; Childers and Tomasello, 2002), or the novel target is the only object present when it is named (e.g., Oviatt, 1980; Dollaghan, 1985). These differences in the methods make it difficult to determine specifically how referent selection and ostensive naming support gradual word learning, and how they are related. In sum, the conclusions that children retain novel words following fast mapping, are tentative at best.

In cases where children are not given the opportunity to engage in referent selection, and are instead explicitly told the target names, children engage in a passive learning process based largely on external input. That is, children are not forming independent inferences about the link between a novel name and a novel referent - although this is what fast mapping should entail (Carey and Bartlett, 1978).

In cases where only one novel object among an array of novel objects is named, children may not be learning the name-object association but rather choosing the target on retention trials because it is the only object with a name among a collection of nameless objects (for a similar argument see Schafer and Plunkett, 1998). Baldwin and Markman (1989) have demonstrated that children attend longer to objects that are named than those which are not, further suggesting they may encode more about the target than the competitors in such situations. For these reasons it is important to introduce a minimum of two novel name-object pairs to ensure children are not demonstrating re-referent-selection when they should be demonstrating retention. Similarly, when only one novel object is present when it is named children may later choose the target on retention trials because it had been singled out as "special" by virtue of being the only object named (for a similar argument see Samuelson and Smith, 1998). Thus, it is difficult to determine the mechanisms that support word learning in these cases because it is unclear that the child really learned a new word and did not simply learn "there is something special about that one, I should pick it again."

Recently, Horst and Samuelson (2008) demonstrated that 24month-old children can only learn words via referent selection when ostensive naming was provided immediately after children's initial choices. Specifically, during the initial referent selection task, they presented children with three-alternative forced-choice trials with three objects, e.g., a target novel object and two known competitors and asked children to "get the fode." Across conditions, after each referent selection trial, children either received no feedback, follow-in labeling (the target was immediately named while the child looked at it), or ostensive naming (the target was pulled back, held up, pointed to, and named while the child looked at it).

To test for long-term memory for the novel names, children were presented with a retention task after a 5-min break. Children were shown three previously seen novel objects: two had served as targets during the referent selection task and one had been seen but not named during a preference control task. When asked for a previous target (e.g., fode), only children who had received ostensive naming demonstrated any evidence of slow mapping. This is particularly important because the only difference between the follow-in labeling and ostensive naming conditions was how the experimenter named the target object. Specifically, the main difference lies in what happened to the known competitors. During follow-in labeling, the competitors were still within children's field of vision, but, during ostensive naming, the competitors were present but outside children's field of vision. The authors argue that ostensive naming facilitated children's ability to effectively encode the name-object associations because it simultaneously highlighted the target object and dampened the effect of the known competitors. That is, ostensive naming exogenously increased children's attention to the target and decreased their attention to the competitors.

In the current study we empirically test Horst and Samuelson's (2008) explanation for why ostensive naming facilitates word learning following referent selection by teasing apart highlighting the target object and dampening the effect of the known competitors. Specifically, we use a specially designed illumination tray to help children attend to the target object (highlighttarget condition), decrease their attention to the known competitors (dampen-competitors condition), or both (highlighttarget/dampen-competitors condition). We also include a control group who are not given such direction. If Horst and Samuelson's explanation for the function of ostensive naming is correct, then children in the highlight-target/dampen-competitors condition should retain words better than children in the other conditions. Further, children whose attention was simultaneously directed toward the target (via highlighting) and away from the competitors (via dampening) should perform better than children who are not given such direction (i.e., the control group).

However, there is another possible explanation for why ostensive naming is so useful for word learning following referent selection. Ostensive naming may facilitate word learning due to social pragmatic cues. A rich literature demonstrates that social pragmatic cues, such as pointing and eye-gaze, are highly beneficial in early word learning (e.g., Akhtar and Tomasello, 1996; Moore et al., 1999; Graham et al., 2010; Grassmann and Tomasello, 2010). Horst and Samuelson (2008) used pointing as a social pragmatic cue during ostensive naming, but no cues during follow-in labeling. Thus, it is possible that children in Horst and Samuelson's (2008) study performed better in the ostensive naming condition 
because of the social pragmatic cue of pointing and not because of the highlighting and dampening of targets and competitors.

In the current study we also empirically test this possible explanation for how ostensive naming facilitates word learning following referent selection by including a control group that receive the same social pragmatic cue as in Horst and Samuelson (2008). If ostensive naming works merely because of a social pragmatic cue, then children in the control condition should successfully retain the novel words.

Thus, in order to better understand the mechanisms underlying children's ability to retain novel names in referent selection tasks when ostensive naming is provided, we attempt to untangle the effects of highlighting the target, dampening the effect of the known competitors, and a social pragmatic cue. In the current study children in all conditions completed the same known and novel-name referent selection trials. The conditions differed in the feedback children received immediately following each known or novel-name referent selection trial: either the experimenter illuminated the target from below, covered the competitors (yet kept them visible), illuminated the target and covered the competitors, or pointed to the target. Children in all conditions completed the same retention trials after a 5-min delay.

\section{MATERIALS AND METHODS PARTICIPANTS}

Forty-eight typically developing 24-month-old children participated $(M=23 \mathrm{~m}, 29$ days, $\mathrm{SD}=50$ days; range $=21 \mathrm{~m}, 17$ days to 27 m, 14 days; 26 girls and 22 boys). Families were recruited from a database of parents interested in participating in child language research. Data from five additional children were excluded from analyses due to experimenter error $(n=2)$, failure to fast map any novel names $(n=1)$, and fussiness $(n=2)$. Twelve children were randomly assigned to each condition: highlight-target (six girls), dampen-competitors (six girls), highlight-target/dampencompetitors (seven girls), and control (pointing, seven girls). There were no differences between conditions in age, $F(3$, $44)=0.75, p=0.53, \eta_{p}^{2}=0.05$, or productive vocabulary $F(3$, $44)=1.20, p=0.32, \eta_{\mathrm{p}}^{2}=0.08$. Parents were reimbursed for travel expenses and children were given a small gift for participating.

\section{STIMULI}

The same stimuli were used in each condition. Fourteen objects, chosen because they are easily named by 24-month-old children, served as known objects. These included six animals (elephant, dog, cow, pig, monkey, duck), three vehicles (car, motorbike, helicopter), and five household objects (plate, block, cup, fork, chair). Four novel objects, chosen because they are not normally familiar to 24-month-old children, served as novel objects. Four distinct CVC non-words were used to name the novel objects, chosen because they adhere to English phonological rules and have been used successfully in previous studies (see Wilkinson and Mazzitelli, 2003; Horst and Samuelson, 2008). Thus, the novel name-object pairs included a massager (fode), a cup-and-ball toy (dite), a beaded, metal spaceship shape (pabe), and a rubber pom-pom (yok). These were the same novel objects used in Horst et al. (2010). Before the experiment began, parents were shown color photographs of both the known and novel objects to ensure that the objects were known and novel, respectively. Additional substitute objects were on hand, but never required. If an alternative name was used by a child for any known object (e.g., "doggy"), then the experimenter used this name. All objects were similar in size (approximate mean size $5 \mathrm{~cm} \times 8 \mathrm{~cm} \times 10 \mathrm{~cm}$ ).

Stimuli were presented on a tray specifically designed for this experiment so that the target objects could be illuminated from below (see Figure 1). The milky white Plexiglas top of the tray was divided into three sections. The gray metal base of the tray consisted of three compartments, which enabled a metal box containing a light bulb to be slotted into any compartment when targets were illuminated from below during ostensive naming in the highlight conditions. Two transparent boxes $(12.50 \mathrm{~cm} \times 11.75 \mathrm{~cm} \times 27.00 \mathrm{~cm})$ fit on the tray and were used when the competitors were covered during ostensive naming in the dampen conditions. The boxes were as small as possible but large enough to fully cover the widest, longest, and tallest objects. A digital kitchen timer was used to time the 5-min break between the referent selection and retention trials.

\section{PROCEDURE AND DESIGN}

During the experiment, children were seated across a white table from the experimenter in a booster seat next to their parent or on their parent's lap. Parents completed a vocabulary checklist (Klee et al., 1999) during the session, and were instructed to only talk to their children if they needed encouragement to respond.

\section{WARM-UP TRIALS}

Each session began with three warm-up trials with the same three known objects on each trial (e.g., car, duck, spoon) to introduce children to the forced-choice task. On each warm-up trial, the experimenter set the tray of objects on the table and silently counted for $3 \mathrm{~s}$ to give children the opportunity to look at the objects. Then, the experimenter asked for the target object, naming it five times, for example, "Where's the car? Can you see the car? Which one is the car? Can you point to the car? Get the

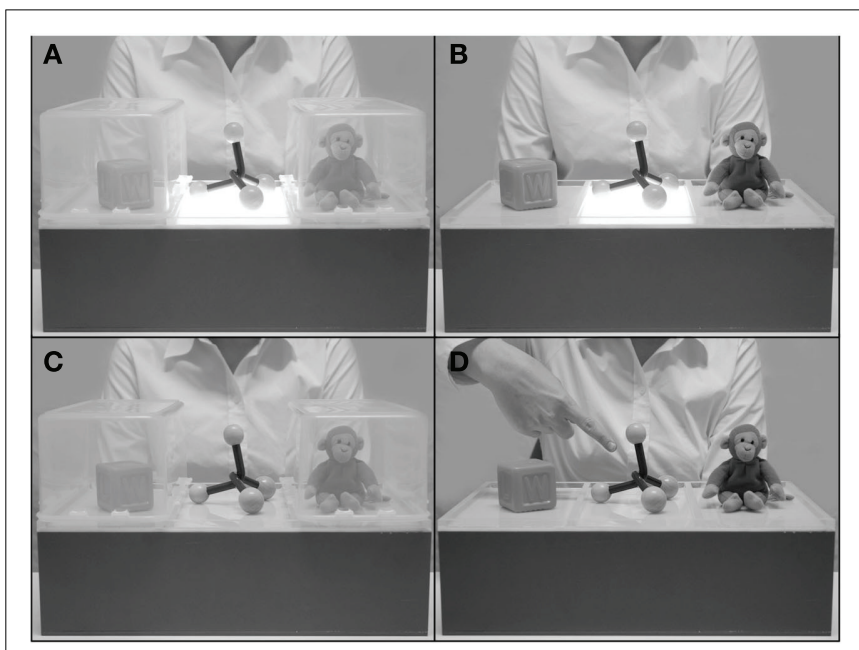

FIGURE 1 | An example of feedback on a fode trial for each condition. (A) Highlight-target/dampen-competitors, (B) highlight-target, (C) dampen-competitors, (D) control (pointing). 
car!" before sliding the tray forward (see also Horst and Samuelson, 2008). Children were praised enthusiastically for correct responses and corrected if necessary, in which case the experimenter helped them find the correct object so that the child could be praised. After the child selected the correct object, the experimenter pulled the tray back and replaced the target object. Then, the experimenter ostensively named the target object in a manner relevant to each condition. Specifically, the experimenter named the object (e.g., "That is the car!"), and either simultaneously illuminated the object from below (highlight-target condition), covered the competitors (dampen-competitors condition), illuminated the target object and covered the competitors (highlighttarget/dampen-competitors condition), or pointed to the object (control condition).

In the conditions where objects were illuminated from below (the highlight-target/dampen-competitors condition and the highlight-target condition), the experimenter placed the light into the correct tray compartment before setting the tray on the table. After the child had made a choice, the experimenter slid the tray back and replaced the object. Then, during ostensive naming, the experimenter discreetly flashed the light on and off four times by using a switch on a cord on her side of the table, out of the child's field of vision. The experimenter named the target while the light was flashing.

In the conditions where objects were covered (the highlight-target/dampen-competitors condition and the dampencompetitors condition), the experimenter had the two transparent boxes to the side (next to the experimenter, across from the parent) and reached for them when needed. After the child had made a choice, the experimenter slid the tray back and replaced the chosen object. Then, the experimenter placed the covers on the competitors and put her hands back in her lap. The experimenter named the target while the competitors were covered. In the highlighttarget/dampen-competitors condition, the experimenter slid the tray back, replaced the chosen object, covered the competitors, put her hands in her lap, and then discreetly flashed the light on and off. That is, the experimenter covered the competitors before flashing the light in the highlight-target/dampen-competitors condition. From the child's perspective, the experimenter always appeared to have her hands in her lap during ostensive naming in all conditions (with the exception of the hand pointing to the target in the control condition, see Figure 1).

During ostensive naming, in all conditions, the experimenter looked straight at the child and did not look at any of the objects on the tray. The experimenter ensured the child was looking at the objects before beginning ostensive naming. If the child was looking elsewhere, e.g., at the parent or floor, the experimenter said the child's name to orient the child back to the task. Note, unlike Horst and Samuelson (2008), the objects' spatial locations relative to each other did not change during ostensive naming, that is, the target was not lifted from the tray. Therefore, the distances between the objects were not a factor, but rather the individual contributions of highlighting, covering, and pointing could be tested. Finally, the experimenter removed the tray from the table and rearranged the objects. Target location (left, middle, right) was pseudo-randomized across trials. Children were asked for a different object in a different position (left, middle, right) on each trial. The warm-up stimuli were not used again during the experiment.

\section{REFERENT SELECTION TRIALS}

The referent selection trials immediately followed and were identical to the warm-up trials except that children were neither praised nor corrected, instead the experimenter simply said, "thank you." After sliding the tray of objects back to its starting point, the experimenter replaced the chosen object and then ostensively named the target depending on condition, as in the warm-up trials. The experimenter ostensively named the target object regardless of whether the child had correctly chosen the target object or incorrectly chosen a competitor. Each child was presented with four sets of objects that each included two known objects (e.g., block and monkey) and one novel object (e.g., massager). Each set was presented twice: once the child was asked for a known object (e.g., block) and once for a novel object (e.g., fode). Known name referent selection trials were included to ensure that children were not learning "choose the novel object" during the experiment, which is especially important as children have an endogenous bias to novelty in referent selection tasks (Horst et al., 2011; see also Merriman and Bowman, 1989). Ostensive naming was provided on both known and novel-name referent selection trials because we believe known and novel names are on a continuum (i.e., every known name was once a novel name) and we therefore wanted to treat the trials the same.

Thus, each child received eight referent selection trials (four known and four novel-name trials). The order of known and novel trials was pseudo-randomized such that the same set was never presented on two consecutive trials and no more than two trials of either type (i.e., known or novel) were presented sequentially. In addition, trial order was also counterbalanced across children to ensure that each novel trial occurred equally often as the first, second, third, etc., novel-name trial in the session. Target location (left, middle, right) was randomly determined on each trial.

\section{DELAY PERIOD}

Following the referent selection task, the child played in the laboratory waiting room during a 5-min delay while the parent continued to work on the vocabulary checklist. None of the objects used in the experiment, known or novel, were present in the waiting room.

\section{RETENTION TRIALS}

The retention task was the same in all four conditions. A new warm-up trial with three new known objects was presented to reengage children in the task. The four retention trials immediately followed. On each trial, the experimenter set the tray of objects on the table and silently counted for $3 \mathrm{~s}$ to give children the opportunity to look at the objects. Then, the experimenter asked for the target object, naming it once, for example, "Can you get the fode?" before sliding the tray forward (see also Horst and Samuelson, 2008). Children were neither praised nor corrected and no ostensive naming was provided on either the retention trials or the new warm-up trial. The experimenter simply said, "thank you." Across trials, children were asked for each novel object once and saw each novel object three times (once as the target, twice as a competitor). Trial order was counterbalanced across children and target 
location (left, middle, right) was randomly determined on each trial. As in previous studies (Horst and Samuelson, 2008; Horst et al., 2011; Kucker and Samuelson, 2011), only the words that children correctly fast-mapped during the referent selection trials were included in the analyses of the child's retention.

\section{CODING}

Sessions were coded off-line from DVD. A second coder, blind to the experimental hypotheses, coded $20 \%$ of the sessions in each condition for inter-coder reliability, which was high $(M=98 \%$, $\mathrm{SD}=3 \%$, range $=94-100 \%$ ).

\section{RESULTS \\ REFERENT SELECTION TRIALS}

As can be clearly seen in Figure 2, children in all four conditions performed very well during the initial referent selection task. On the known name referent selection trials, children chose the target object significantly more than would be expected by chance (0.33) in the highlight-target/dampencompetitors condition $[t(11)=9.47, p<0.001, d=2.73]$, the highlight-target condition $[t(11)=8.96, p<0.001, d=2.59$ ], the dampen-competitors condition $[t(11)=8.71, p<0.001$, $d=2.51]$, and the control condition $[t(11)=22.37, p<0.001$, $d=6.46]$. Children's proportions of target choices on the known name referent selection trials were submitted to an ANOVA with condition (highlight-target/dampen-competitors, highlighttarget, dampen-competitors, control) as a between-subjects factor. The ANOVA yielded no significant effects, indicating that the type of feedback - that is, which form of ostensive naming - children received after their choices did not influence their ability to select familiar objects.

Similarly, on the novel-name referent selection trials, children chose the target object significantly more than would be expected by chance $(0.33)$ in the highlight-target/dampencompetitors condition $[t(11)=4.04, p=0.002, d=1.17]$, the highlight-target condition $[t(11)=4.97, p<0.001, d=1.43]$, the dampen-competitors condition $[t(11)=8.96, p<0.001$, $d=2.59]$, and the control condition $[t(11)=10.86, p<0.001$, $d=3.14$ ]. Children's proportions of target choices on the

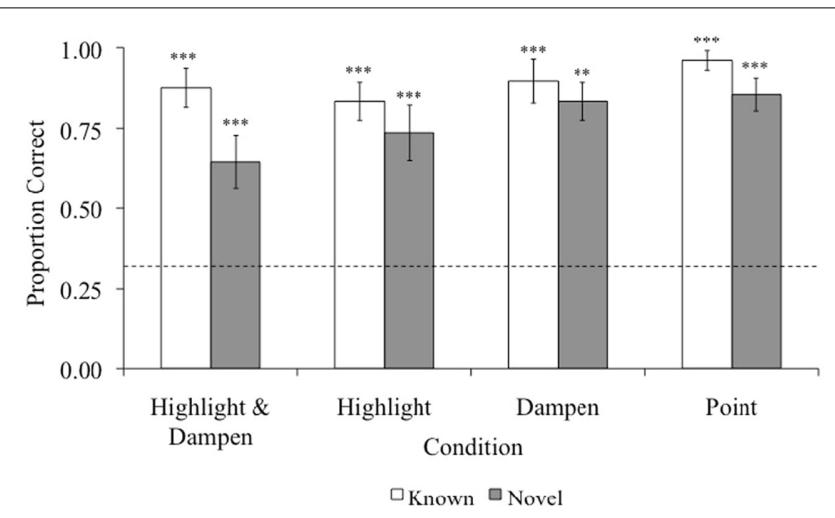

FIGURE 2 | Children's proportion of correct choices during the referent selection task. Dotted line represents chance (0.33). Error bars represent 1 SE. ${ }^{* *} p<0.001,{ }^{*} p<0.02$. novel-name referent selection trials were submitted to an ANOVA with condition (highlight-target/dampen-competitors, highlighttarget, dampen-competitors, control) as a between-subjects factor. The ANOVA yielded no significant effects. Thus, the type of feedback children received after their choices did not influence their ability to determine the referent of novel names on these trials.

\section{RETENTION TRIALS}

In contrast, the type of feedback provided during referent selection did influence children's retention of previously fast-mapped novel names after a 5-min delay. As can be seen in Figure 3, children in the highlight-target/dampen-competitors condition retained novel names at rates significantly greater than expected by chance (0.33), $t(11)=3.01, p=0.01$, two-tailed, $d=0.87$. Children in the highlight-target condition also demonstrated significant retention (0.33), $t(11)=2.30, p=0.04$ two-tailed, $d=0.66$. However, children's retention of novel names was only marginally different from chance (0.33) for children in the dampen-competitors condition, $t(11)=2.13, p=0.057$, two-tailed, $d=0.61$. In contrast, children in the control condition performed at chance levels $t(11)=-0.27$, $p=0.79$, two-tailed, $d=0.08$. Thus, highlighting the target object after children's choices during the referent selection task facilitated novel-name retention and simultaneously dampening children's attention to the known competitors by covering may also have aided retention.

To best understand the individual contributions of highlighting the target objects and dampening attention to the known competitors during referent selection on children's ability to later retain the novel names, children's proportion of target choices on the retention trials was submitted to an ANOVA with highlight (yes, no) and dampen (yes, no) as between-subjects factors ${ }^{1}$. The ANOVA yielded a main effect of highlight, $F(1$, $44)=4.81, p=0.03, \eta_{\mathrm{p}}^{2}=0.10$. Children in the highlight conditions (highlight-target/dampen-competitors and highlight-target)

${ }^{1}$ For the purposes of this ANOVA, the current experiment can be considered a $2 \times 2$ design with highlight and dampen as between-subjects factors yielding four conditions: highlight-target/dampen-competitors (highlight, dampen), highlight-target (highlight, no dampen), dampen-competitors (no highlight, dampen), and control (no highlight, no dampen).

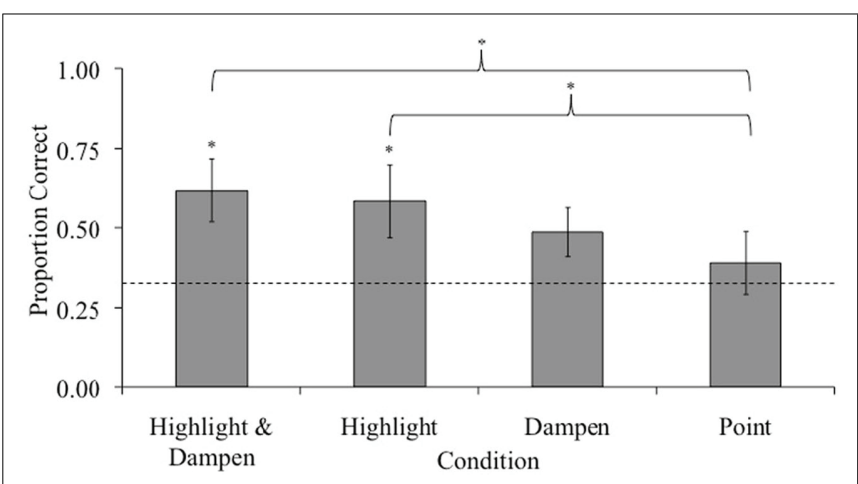

FIGURE 3 | Children's proportion of correct choices during the retention task. Dotted line represents chance (0.33). Error bars represent 1 SE. ${ }^{*} p<0.025$. 
retained more words $(M=0.60, \mathrm{SD}=0.36)$ than children in the non-highlight conditions (dampen-competitors and pointing; $M=0.40, \mathrm{SD}=0.30$ ). No other significant effects were found. In addition, a one-way ANOVA comparing retention scores between the four conditions was non-significant, $F(3,44)=2.25$, $p=0.096, \eta_{\mathrm{p}}^{2}=0.13$. However, there was a significant linear trend, $F(1,44)=5.35, p=0.03, R^{2}=0.133$, indicating that retention increased from pointing, to covering the competitors, to illuminating the target to both illuminating the target and covering the competitors. Planned contrasts ${ }^{2}$ using Bonferroni adjustments comparing the control condition to each of the highlight conditions revealed significant differences in the proportion of words retained between children in the control condition and both children in the highlight-target/dampen-competitors condition, $t(22)=2.36, p=0.01$, one-tailed, $d=0.94$, and children in the highlight-target condition, $t(22)=2.11, p=0.02$, one-tailed, $d=0.76$. Overall, then, children retained novel names if their attention had been directed toward the target during referent selection. However, receiving support in the form of a common social pragmatic cue (pointing) did not lead to retention at levels different from chance. Taken together, these data demonstrate that highlighting the target object has the strongest effect on children's ability to retain novel names.

\section{DISCUSSION}

The current study examined how ostensive naming facilitates young children's word learning following referent selection. Specifically, to better understand how exogenous attentional cues aid encoding of novel name-object associations, we teased apart two factors of ostensive naming: highlighting the target object and decreasing attention to the known competitors. Twenty-fourmonth-old children completed a referent selection task with four types of feedback: either the experimenter illuminated the target from below, covered the competitors (yet kept them visible), illuminated the target and covered the competitors, or pointed to the target. Across all four conditions, children performed equally well during referent selection. However, the type of ostensive naming children received immediately after their referent selection trials affected their retention after a 5-min delay. Children who saw the target object illuminated retained words at greater than chance levels, and greater than children who received feedback via a social pragmatic cue (pointing).

The current study builds directly on previous research by Horst and Samuelson (2008) on children's ability to learn words following referent selection when ostensive naming is provided. In a series of studies they demonstrated that despite 24-month-old children's proficiency in referent selection, they were unable to demonstrate any word learning unless ostensive naming was provided immediately after their initial selections. In that study, ostensive naming consisted of lifting the target object away from the

\footnotetext{
${ }^{2}$ The appropriateness of reporting follow-up analyses when the initial ANOVA is non-significant is a contentious issue. Howell (2002) and Wilcox (1987) both argue that as the ANOVA and the follow-up analyses are different tests with different hypotheses, significant follow-up analyses should not be ignored following a non-significant overall test. The planned contrasts reported here were of particular interest to this study. Determining whether the experimental conditions were each better than the control group (pointing) was considered necessary to report.
}

others, pointing to it and naming it. The authors argue that such ostensive naming facilitated word learning by directing children's attention, specifically by simultaneously highlighting the target while reducing children's attention to the known competitors. This is one possibility, which is also in line with similar accounts of how children learn words via referent selection (Capone and McGregor, 2005; Horst et al., 2006; McMurray et al., 2009). An alternative explanation is that the pointing in the Horst and Samuelson task served as a social pragmatic cue that facilitated word learning. Previous research demonstrates that children do use social pragmatic cues to determine the referent of novel names in ambiguous word learning situations (e.g., Moore et al., 1999; Grassmann and Tomasello, 2010). The current study also tested this possibility by including a control group, in which children received feedback via the experimenter pointing to the target object. The results reported here clearly demonstrate that the attention-directing feedback led to better novel word learning.

This makes intuitive sense because referent selection is often considered to be a process-of-elimination task (e.g., Halberda, 2003). On this view, children need to attend to and rule out the known competitors, but committing the novel name-object association to memory requires that children also focus their attention on the novel object immediately following referent selection. Highlighting the target object immediately after children's referent selection helps direct their attention to that object. At the same time, covering the known competitors (when combined with highlighting) directs children's attention away from those objects. Together, both of these cues help children focus their attention on the to-be-remembered object, which in turn facilitates encoding and learning the novel name-object association.

It is worth noting, that where target objects are positioned in visual space is also likely to be important in toddlers' learning about novel names and objects (see also Samuelson et al., 2011). Recent research by Smith et al. (2011, see also Yoshida and Smith, 2008) found that the way toddlers attend to and manipulate objects differs to that of adults. Using head-mounted cameras they demonstrated that young children appear to typically grasp objects, bringing them close to their eyes. Thus, the size and focus of objects change regularly and children appear to attend to a single object at a time. Adults, on the other hand, typically view multiple objects simultaneously and the size of the objects remains relatively constant. These findings suggest that the highlighting and dampening cues in the current study likely aided children's word learning via referent selection by helping them to focus on one object at a time.

Previous research on children's ability to demonstrate longterm learning of novel names have also highlighted the target and/or decreased children's attention to the competitors, although the methods and results are rarely discussed this way. Thus, the insights from the current study regarding directing children's attention toward the target and away from the competitors may shed light on these previous findings.

Children have been very successful at choosing the target objects in studies where only one novel object is named (e.g., Woodward et al., 1994; Markson and Bloom, 1997; Akhtar et al., 2001). For example, Markson and Bloom (1997) created a game in which children either measured a novel object or were told that the target object had a special feature (e.g., it was a gift from 
the experimenter's uncle or a sticker was placed on it), but only one name was introduced. Even 1 month later, 3- and 4-year-old children were able to identify the target object. Again, the target object was effectively highlighted because it was the only object being named. Similarly, Dollaghan (1985) also only named a single novel target object. In this study, children were presented with two known objects and one novel object. Children were first asked to put each of the known objects out of sight, consequently, the target object was the only object present when it was named. Children successfully selected the target on a post-test even in the context of new novel (unnamed) objects. Thus, training with the target object on its own not only helped highlight it, by virtue of being the only novel object encountered during the study, but also dampened children's attention to the known competitors as they were physically removed from the problem space. Note, when only a single novel name-object association is introduced, it is not clear whether children's later performance is really due to their retention of the novel name or simple due to their memory that the target object was "special" because it had been the only object named and therefore singled out (for a similar argument see Schafer and Plunkett, 1998).

A series of previous experiments suggests that children are very sensitive to objects being singled out and that they map novel names to singled-out objects. For example, 2-year-old children will map a novel name to the only novel object that was played with when a speaker was absent (Akhtar et al., 1996), that was the only novel object played with in a new, unique location, such as on a glittery tablecloth (Samuelson and Smith, 1998), and that was the only novel object accidentally dropped (Diesendruck et al., 2004). In each of these cases, children will map a novel name to the most novel object (see also Horst et al., 2011). In light of the current study, this effect may be due to the saliency of the target object.

There may be multiple ways to increase the saliency of the target object, and some ways may be more relevant to endogenous attention (e.g., only labeling one novel object, only having one object present when the novel name is introduced), while others may better be described as exogenous attentional cues (e.g., playing with the target on a glittery tablecloth). Each of these methods likely helps sustain children's attention on the target object, which in turn facilitates the processing and encoding of information about the novel object, the novel name, and their association, such that this information can be recalled after a delay. In the current study, we quite literally highlight the target via illumination. Importantly, with each of these methods attention is directed to the target object by singling it out. For example, in all of the conditions of the current study, the target was always singled out as it was the only object illuminated, the only object left uncovered or the only object pointed to, while the attention was always directed away from the competitors as they were covered, not illuminated and not pointed to. These conditions, then, could be viewed as being on a continuum of target saliency, that is, of the effectiveness that

\section{REFERENCES}

Adolph, K. E., and Eppler, M. A. (1998). Development of visually guided locomotion. Ecol. Psychol. 10, 303-321.

these exogenous cues had in focusing children's attention to the target object. This continuum is reflected in the significant linear trend in retention scores. Pointing to the target object was perhaps least effective as it did not sufficiently draw children's attention to the target. In the conditions where the target object was illuminated, children's attention was likely more strongly drawn to the novel target, which helped them encode and later retain the novel name-object association. Future research is needed to determine when these cues are most effective and whether their effectiveness varies over the course of word learning, and early development.

Overall, then, the current study illustrates that directing children's attention to specific targets following referent selection enhances memory for novel name-object associations. Attention to all of the objects followed by more focused attention to the novel object facilitates long-term learning. Children in the current study demonstrated significant retention when the target was illuminated, and when the target was illuminated and the known competitors were covered by transparent boxes. Importantly, in both of these conditions, the known competitors were never completely out of children's field of vision as the target remained on the same tray (cf. Horst and Samuelson, 2008). These results suggest that highlighting the target is crucial for retention and that dampening attention to competitors may incrementally aid in the encoding of the target object.

Although children examine objects one at a time, when possible (Yoshida and Smith, 2008; Smith et al., 2011), word learning does not occur in a vacuum. Rather, children's experience outside the laboratory includes relatively cluttered environments where they are often seeing multiple objects when they hear a new word. In fact, these cluttered environments support children's crosssituational, gradual word learning (Horst et al., 2006, see also Yu and Smith, 2007; Smith and Yu, 2008). Moreover, because children often do see multiple objects when they hear a novel name it is especially useful to provide support to focus their attention on the right thing at the right time to facilitate the remarkable accomplishment that is vocabulary acquisition.

\section{ACKNOWLEDGMENTS}

This research was funded by ESRC grant number RES-000-224451 to Jessica Horst. Portions of these data were presented at the 2010 Biennial Meeting for the International Society for Infant Studies (Baltimore, MD, USA) and the 2011 Biennial Meeting for the Cognitive Development Society (Philadelphia, PA, USA). We are grateful to Larissa Samuelson and Bob McMurray for previous discussions of the theoretical motivation for this research and the methods used. We would like to thank the members of the Word Lab, especially Holly Paddock and Alison Murphy for help with data collection and Matthew Hilton for help with coding. We would like to thank Ryan Kavlie for help creating Figure $\mathbf{1}$ and Andy Field for discussions on the statistics. Finally, we would also like to thank the parents and children who participated, without whom this research would not be possible.

discourse novelty in early word learning. Child Dev. 67, 635-645.

Akhtar, N., Jipson, J., and Callanan, M. A. (2001). Learning words through overhearing. Child Dev. 72, 416-430.
Akhtar, N., and Tomasello, M. (1996). Two-year-olds learn words for absent objects and actions. Br. J. Dev. Psychol. 14, 79-93. 
Baldwin, D. A., and Markman, E. M. (1989). Establishing word-object relations: a first step. Child Dev. 60, 381-398.

Capone, N. C., and McGregor, K. K. (2005). The effect of semantic representation on toddler's word retrieval. J. Speech Lang. Hear. Res. 48, 1468-1480.

Carey, S. (1978). "The child as word learner," in Linguistic Theory and Psychological Reality, eds M. Halle, J. Bresnan, and A. Miller (Cambridge: MIT Press), 264-293.

Carey, S., and Bartlett, E. (1978). Acquiring a single new word. Proc. Stanford Child Lang. Conf. 15, 17-29.

Childers, J. B., and Tomasello, M. (2002). Two-year-olds learn novel nouns, verbs, and conventional actions from massed or distributed exposures. Dev. Psychol.38, 967-978.

Diesendruck, G., Markson, L., Akhtar, N., and Reudor, A. (2004). Two-yearolds' sensitivity to speakers' intent: an alternative account of Samuelson and Smith. Dev. Sci. 7, 33-41.

Dollaghan, C. (1985). Child meets word - fast mapping in preschool children. J. Speech Hear. Res. 28, 449-454.

Fenson, L., Dale, P. S., Reznick, J. S., Bates, E., Thal, D., and Pethick, S. (1994). Variability in early communicative development. Monogr. Soc. Res. Child Dev. 59, v-173.

Gokhale, R., and Kirschner, B. S. (2003). Assessment of growth and nutrition. Best Pract. Res. Clin. Gastroenterol. 17, 153-162.

Golinkoff, R. M., Hirsh-Pasek, K., Bailey, L. M., and Wenger, N. R. (1992). Young-children and adults use lexical principles to learn new nouns. Dev. Psychol. 28, 99-108.

Goodman, J. C., McDonough, L., and Brown, N. B. (1998). The role of semantic context and memory in the acquisition of novel nouns. Child Dev. 69, 1330-1344.

Graham, S. A., Nilsen, E. S., Collins, S., and Olineck, K. (2010). The role of gaze direction and mutual exclusivity in guiding 24-month-olds' word mappings. Br. J. Dev. Psychol. 28, 449-465.

Grassmann, S., and Tomasello, M. (2010). Young children follow pointing over words in interpreting acts of reference. Dev. Sci. 13, 252-263.
Halberda, J. (2003). The development of a word-learning strategy. Cognition 87, B23-B34.

Heibeck, T. H., and Markman, E. M. (1987). Word learning in children an examination of fast mapping. Child Dev. 58, 1021-1034.

Horst, J. S., McMurray, B., and Samuelson, L. K. (2006). "Online processing is essential for leaning: understanding fast mapping and word learning in a dynamic connectionist architecture," in Proceedings from the 28th Meeting of the Cognitive Science Society, Vancouver, 339-344.

Horst, J. S., and Samuelson, L. K. (2008). Fast mapping but poor retention by 24-month-old infants. Infancy 13, 128-157.

Horst, J. S., Samuelson, L. K., Kucker, S. C., and McMurray, B. (2011). What's new? Children prefer novelty in referent selection. Cognition 118, 234-244.

Horst, J. S., Scott, E. J., and Pollard, J. A. (2010). The role of competition in word learning via referent selection. Dev. Sci. 13, 706-713.

Howell, D. C. (2002). Statistical Methods for Psychology. Belmont: Thomson Wadsworth.

Klee, T., Marr, C., Robertson, E., and Harrison, C. (1999). The MacArthur Communicative Development Inventory: Toddler. Newcastle: Newcastle University. [British English adaptation].

Kucker, S. C., and Samuelson, L. K. (2011). The first slow step: differential effects of object and wordform familiarization on retention of fast-mapped words. Infancy. doi: 10.1111/j.1532-7078.2011.00081.x

Lampl, M., Veldhuis, J. D., and Johnson, M. L. (1992). Saltation and stasis: a model of human growth. Science 258, 801-803.

Markson, L., and Bloom, P. (1997). Evidence against a dedicated system for word learning in children. Nature $385,813-815$.

Mather, E., and Plunkett, K. (2009). Learning words over time: the role of stimulus repetition in mutual exclusivity. Infancy 14, 60-76.

McMurray, B., Horst, J. S., Toscano, J. and Samuelson, L. K. (2009). "Connectionist learning and dynamic processing: symbiotic developmental mechanisms," in Towards a
New Grand Theory of Development? Connectionism and Dynamic Systems Theory Reconsidered, eds J. P. Spencer, M. Thomas, and J. McClelland (New York: Oxford University Press), 218-249.

Merriman, W. E., and Bowman, L. L. (1989). The mutual exclusivity bias in children's word learning. Monogr. Soc. Res. Child Dev. 54, 1-129.

Mervis, C. B., and Bertrand, J. (1994). Acquisition of the novel name nameless category $(\mathrm{N} 3 \mathrm{c})$ principle. Child Dev. 65, 1646-1662.

Moore, C., Angelopoulos, M., and Bennett, P. (1999). Word learning in the context of referential and salience cues. Dev. Psychol. 35, 60-68.

Needham, A., Barrett, T., and Peterman, K. (2002). A pick-me-up for infants' exploratory skills: early simulated experiences reaching for objects using 'sticky mittens' enhances young infants' object exploration skills. Infant Behav. Dev 25, 279-295.

Oviatt, S. L. (1980). The emerging ability to comprehend language: an experimental approach. Child Dev. 51, 97-106.

Riches, N. G., Tomasello, M., and ContiRamsden, G. (2005). Verb learning in children with SLI: frequency and spacing effects. J. Speech Lang. Hear. Res. 48, 1397-1411.

Rutter, D. R., and Durkin, K. (1987), Turn-taking in mother-infant interaction: an examination of vocalizations and gaze. Dev. Psychol. 23, 54-61.

Samuelson, L. K., and Smith, L. B. (1998). Memory and attention make smart word learning: an alternative account of Akhtar, Carpenter, and Tomasello. Child Dev. 69, 94-104.

Samuelson, L. K., Smith, L. B., Perry, L. K., and Spencer, J. P. (2011). Grounding word learning in space. PLoS ONE 6, e28095. doi:10.1371/journal.pone.0028095

Schafer, G., and Plunkett, K. (1998). Rapid word learning by fifteenmonth-olds under tightly controlled conditions. Child Dev. 69, 309-320.

Smith, L. B., and Yu, C. (2008). Infants rapidly learn word-referent mappings via cross-situational statistics. Cognition 106, 1558-1568.

Smith, L. B., Yu, C., and Pereira, A. F. (2011). Not your mother's view: the dynamics of toddler visual experience. Dev. Sci. 14, 9-17.

Thelen, E., Corbetta, D., Kamm, K., Spencer, J. P., Schneider, K., and Zernicke, R. F. (1993). The transition to reaching: mapping intention and intrinsic dynamics. Child Dev. 64, 1058-1098.

Waxman, S. R., and Booth, A. E. (2000). Principles that are invoked in the acquisition of words, but not facts. Cognition 77, B33-B43.

Wilcox, R. R. (1987). New designs in analysis of variance. Annu. Rev. Psychol. 38, 29-60.

Wilkinson, K. M., and Mazzitelli, K. (2003). The effect of 'missing' information on children's retention of fast-mapped labels. J. Child Lang. 30, 47-73.

Woodward, A. L., Markman, E. M., and Fitzsimmons, C. M. (1994). Rapid word learning in 13- and 18-month-olds. Dev. Psychol. 30, 553-566.

Yoshida, H., and Smith, L. B. (2008). What's in view for toddlers? Using a head camera to study visual experience. Infancy 13, 229-248.

Yu, C., and Smith, L. B. (2007). Rapid word learning under uncertainty via cross-situational statistics. Psychol. Sci. $18,414-420$.

Conflict of Interest Statement: The authors declare that the research was conducted in the absence of any commercial or financial relationships that could be construed as a potential conflict of interest.

Received: 09 October 2011; accepted: 07 March 2012; published online: 28 March 2012.

Citation: Axelsson EL, Churchley $K$ and Horst JS (2012) The right thing at the right time: why ostensive naming facilitates word learning. Front. Psychology 3:88. doi: 10.3389/fpsyg.2012.00088

This article was submitted to Frontiers in Developmental Psychology, a specialty of Frontiers in Psychology.

Copyright (c) 2012 Axelsson, Churchley and Horst. This is an open-access article distributed under the terms of the Creative Commons Attribution Non Commercial License, which permits noncommercial use, distribution, and reproduction in other forums, provided the original authors and source are credited. 